\title{
Normal Rectal Filling Sensations in Patients with an Enlarged Rectum
}

\author{
Sanne J. Verkuijl ${ }^{1}$ Monika Trzpis ${ }^{1}$ Paul M. A. Broens ${ }^{1,2}$
}

Received: 14 March 2018 / Accepted: 5 July 2018 / Published online: 12 July 2018

(c) The Author(s) 2018

\begin{abstract}
Background Increased rectal volume is believed to be associated with diminished rectal sensation, i.e., rectal hyposensitivity. Aims To demonstrate that patients with increased rectal volumes do not automatically have diminished rectal filling sensations.

Methods We, retrospectively, observed 100 adult patients with defecation problems, and 44 healthy controls who had undergone anorectal function tests. Using the balloon retention test, we analyzed the distribution of rectal volumes and pressures at different rectal filling sensation levels.

Results We found variance in the distribution of rectal volumes at all levels, while rectal pressures showed a normal distribution. We found no correlation between rectal volumes and pressures (constant sensation, $r=0.140, P=0.163$, urge sensation, $r=-0.090, P=0.375$, and maximum tolerable volumes, $r=-0.091, P=0.366$ ), or when taking age and sex into account. The findings for the patient group were congruent with those for the control group.

Conclusions Participants with increased rectal volumes do not experience increased rectal pressures at any sensation level. This finding, combined with the knowledge that rectal pressure triggers rectal filling sensation, indicates that rectal filling sensations in patients with increased rectal volumes are not diminished. Therefore, "rectal hyposensitivity" should be reserved for patients with increased rectal pressure thresholds, and not for "abnormally" increased rectal volume thresholds.
\end{abstract}

Keywords Anorectal manometry $\cdot$ Rectal hyposensitivity $\cdot$ Filling sensation $\cdot$ Chronic constipation

\section{Introduction}

Currently, rectal hyposensitivity (RH) is often defined as diminished sensation in reaction to rectal filling $[1,2]$. During clinical measurements, generally performed by inserting predetermined volumes of water in a rectal balloon, the rectal filling sensation is evoked by mechanical distension of the rectum [3-6]. Usually, the thresholds of volumes at

Sanne J. Verkuij1

s.j.verkuijl@umcg.nl

Monika Trzpis

m.trzpis-bremer@umcg.nl

Paul M. A. Broens

p.m.a.broens@umcg.nl

1 Department of Surgery, Anorectal Physiology Laboratory, University of Groningen, University Medical Center Groningen, Groningen, The Netherlands

2 Department of Surgery, Division of Pediatric Surgery, University of Groningen, University Medical Center Groningen, Groningen, The Netherlands which patients report certain filling sensations are registered and patients with an enlarged rectum are often classified as being hyposensitive to rectal filling. As a consequence, current studies investigating anorectal pathophysiology often relate $\mathrm{RH}$ to increased rectal volume, a condition frequently observed in, for instance, chronically constipated patients $[5,7]$. Indeed, RH occurs in 18-68 percent of constipated patients [8]. Nevertheless, the physiological relationship between these two problems is not yet fully understood [2, $4,8-11]$.

Despite the clinical use of volume-based diagnoses of $\mathrm{RH}$, earlier research demonstrated that a diagnosis based on rectal volume thresholds may be incorrect $[1,9,12]$. Since volume thresholds are highly biased by abnormal rectal properties (i.e., increased rectal diameter), they may lead to a false interpretation of nerve pathways [1,9]. This has, however, never been explored in patients using conventional volume-based anorectal manometry, even though this equipment is most commonly used in clinical practice [13]. Conventional manometry can be used to measure both rectal volume and rectal pressure. It was found that rectal 
pressure triggers the rectal filling sensation [5]. Changes in intrarectal pressure activate tension-activated stretch receptors in the rectal wall, which in turn lead to the perception of rectal filling [5, 9, 14, 15]. Following from this, we expect that a population with comparable rectal pressures would perceive rectal filling sensation levels in the same way, irrespective of their rectal volumes. Our aim was to investigate whether there is an association between rectal filling sensation, determined by rectal pressure, and rectal volume. Put differently, are increased rectal volume thresholds, obtained using conventional volume-based rectal distensions, reliable indicators of rectal hyposensitivity?

\section{Methods}

\section{Study Population}

Retrospectively, between March 2010 and January 2015, we reviewed the medical records of patients older than 17 years who had undergone anorectal function tests for defecation problems $(N=246)$. Altogether we excluded 146 patients for the following reasons: a medical history of neurological dysfunction $(n=40)$, a history of pelvic floor surgery with a possible influence on anorectal function $(n=56)$, congenital abnormalities in anorectal function $(n=13)$, other anorectal abnormalities $(n=26)$, including rectovaginal fistula and radiotherapy in the pelvic floor area, or involuntary loss of the balloon during testing $(n=11)$ (Fig. 1). Finally, we included the data of 100 patients for analysis.

We also recruited a control group of healthy participants $(n=44)$, who were informed about this study by digital advertisement. These participants filled out the extensive Groningen Defecation and Fecal Continence $(\mathrm{DeFeC})$ checklist, which allowed us to assure that they had no anorectal dysfunctions [16]. The control group was subjected to the same anorectal function tests as the patient group and gave their informed consent.

The study was conducted at the Anorectal Physiology Laboratory of the University Medical Center Groningen, the Netherlands. The study protocol conforms to the ethical guidelines of the 1964 Declaration of Helsinki and its later amendments. The study "Characteristics of rectal functioning in patients with defecation problems" was granted permission by our local Medical Ethics Review Board in January 2016.

\section{Balloon Retention Test}

The data were obtained by administering the balloon retention test, a standard test in anorectal manometry [17]. It

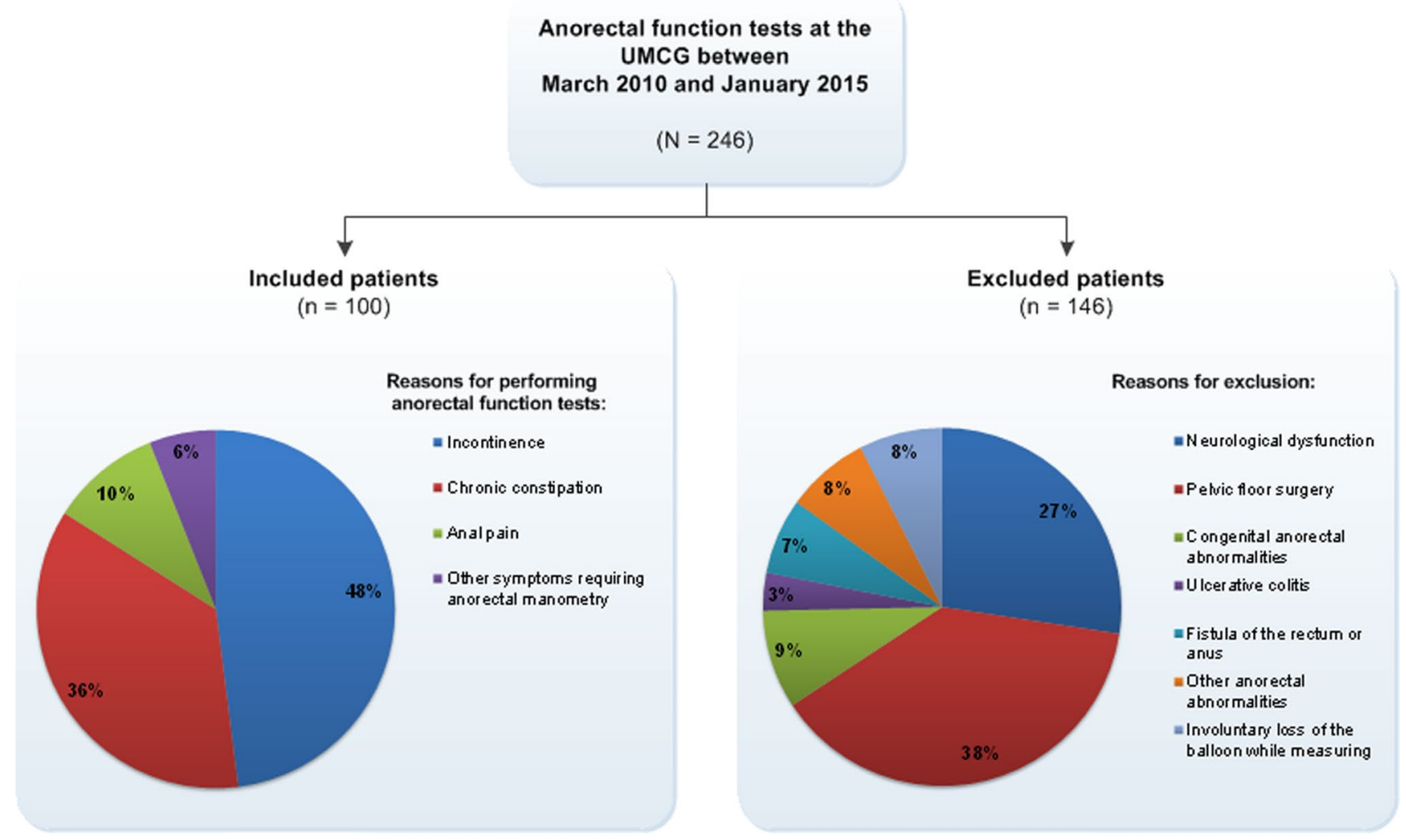

Fig. 1 Overview of the inclusion and exclusion procedure 
provides information about the pressures and volumes at which rectal filling sensations are perceived. Patients were instructed to void rectal contents if possible. Testing started by inserting a catheter, with a deflated balloon attached to its tip, into the rectum. The balloon was pulled slightly toward the pelvic floor. Subsequently, the participant was asked to sit upright on a commode seat while the balloon was filled with $37{ }^{\circ} \mathrm{C}$ water at a rate of $1.0 \mathrm{~mL} / \mathrm{s}$. At the same time, the pressure inside the rectal balloon was measured as well as the volume of water that had been inserted [17]. The participant was instructed to retain the rectal balloon for as long as possible and to report, in consecutive order, constant sensation (CS), urge sensation (US), and maximum tolerable volume (MTV). The test was stopped when the participant reported MTV or when he or she lost the balloon involuntary.

We collected and analyzed the data with solar, gastrointestinal, high-resolution manometry equipment, Version 8.23 (Laborie/Medical Measurement Systems, Enschede, the Netherlands) using customized solid-state circumferential catheters and microtip pressure transducer catheters (Laborie/Unisensor, Wiesendangen, Switzerland), as previously described [17].

\section{Statistical Analysis}

All analyses were made using IBM SPSS Statistics, Version 23.0 for Windows (IBM SPSS Statistics, IBM Corporation, Armonk, NY). The graphs were made using Graphpad Prism, Version 5.04 and the figure was made with Microsoft Visio 2010. The Shapiro-Wilk test was used to evaluate the normality of the data. Since the variables were not distributed normally, we used nonparametric tests and reported the median, minimum, and maximum values. The Mann-Whitney test was performed to compare the results of the patients and the healthy control group. Spearman correlation was used to analyze the correlation between rectal volumes and pressures at the different rectal sensation levels, and MTV. Two-sided $P$ values of less than 0.05 were considered statistically significant.

\section{Results}

\section{Participant Characteristics}

The majority of the patient group suffered from incontinence (48\%) or chronic constipation (36\%), others underwent anorectal manometry for anal pain (10\%) or other symptoms (6\%) (Fig. 1). There were relatively fewer men in the patient group than in the control group (30 vs $38.6 \%$, respectively, $P=0.309$ ). The patient group was significantly older than the control group (median age 50.9 vs 22.2 years, respectively, $P<0.001$ ). Table 1 shows the median rectal volumes and pressures at all rectal sensation levels and the MTVs of the patient group and the control group. At each of the sensation levels investigated, namely CS, US, and MTV, the median rectal volumes differed significantly between the patients and the control groups $(P=0.004, P=0.028$, and $P<0.001$, respectively). The median rectal pressures for the sensation levels only showed a significant difference at US and MTV $(P=0.014$ and $P<0.001$, respectively). All the characteristics are summarized in Table 1.

\section{Distribution of Rectal Volume and Pressure at the Different Rectal Sensation Levels and MTV}

First, we analyzed the distribution of rectal volumes and pressures graphically (Fig. 2). We found that the rectal volumes of all participants at CS were not normally distributed in either the patient group or the healthy control group (Fig. 2a), while the distribution of rectal pressure at CS was similar to the Bell curve for both groups, indicating a normal distribution (Fig. 2d). Rectal volumes at US and MTVs also seemed to be abnormally distributed (Fig. 2b, c), while rectal pressures at these levels showed normal distributions (Fig. 2e, f). We also found that the distribution of rectal volumes and rectal pressures of three subgroups of patients, namely patients with different clinical characteristics (fecal incontinence, constipation and anal pain) was the same as the one observed in the total patients' group (Appendix, Fig. 4).

The above observations from the graphic representation of the distributions of rectal volumes and pressures at the different rectal sensation levels and MTVs were confirmed by statistical analyses of the normality of these distributions (Table 2). We found that the rectal volumes at both CS, US, and MTV were significantly different from the normal distributions $(P<0.001$ for all levels). Likewise, the rectal volumes of the healthy control group also showed a significant difference from the normal distributions at CS and MTV $(P<0.001$ and $P=0.024$, respectively).

However, all but one of the rectal pressures of the patient group and the healthy control group did not differ significantly from a normal distribution. The only exception to this finding was the rectal pressure at CS in the patient group $(P=0.039)$. This indicates that except for the pressure at $\mathrm{CS}$, all rectal pressures were distributed normally, in contrast to the abnormal distributions of rectal volumes in both the patient group and the healthy control group (Table 2).

\section{Correlation Between Rectal Volume and Pressure}

We found no correlation between rectal volumes and pressures in the patient group, at either CS $(r=0.140, P=0.163)$, US $(r=-0.090, P=0.375)$, or MTV $(r=-0.091, P=0.366)$. In the healthy control group, we found only a weak correlation between rectal volumes and pressures at CS $(r=0.314$, $P=0.040)$, US $(r=0.421, P=0.004)$, and maximum tolerable pressure $(r=0.340, P=0.024)$. In Fig. $3 \mathrm{a}-\mathrm{c}$, this analysis 
Table 1 Comparison of baseline characteristics between the patients and the healthy controls

\begin{tabular}{|c|c|c|c|}
\hline $\begin{array}{l}\text { Baseline } \\
\text { characteristics }\end{array}$ & $\begin{array}{l}\text { Patients } \\
(n=100)\end{array}$ & $\begin{array}{l}\text { Healthy } \\
\text { controls } \\
(n=44)\end{array}$ & $P$ value \\
\hline \multicolumn{4}{|l|}{ Demographics } \\
\hline \multicolumn{3}{|l|}{ Sex, $n(\%)$} & \multirow[t]{3}{*}{0.309} \\
\hline Men & $30(30)$ & $17(38.6)$ & \\
\hline Women & $70(70)$ & $27(61.4)$ & \\
\hline $\begin{array}{l}\text { Age (years), median } \\
\quad(\text { minimum-maximum) }\end{array}$ & $50.9(18-81)$ & $22.2(19-31)$ & $<0.001 * *$ \\
\hline \multicolumn{4}{|c|}{ Sensation to balloon distension } \\
\hline \multicolumn{4}{|c|}{ Constant sensation, median (range) } \\
\hline Rectal volume (mL) & $95(10-440)$ & $70(23-290)$ & $0.004 * *$ \\
\hline $\begin{array}{l}\text { Rectal pressure } \\
\quad(\mathrm{mm} \mathrm{Hg})\end{array}$ & $39(20-59)$ & $38(17-57)$ & 0.305 \\
\hline $\begin{array}{l}\text { Rectal compliance (mL/ } \\
\text { mmH g) }\end{array}$ & $2.6(0.3-14.3)$ & $2.0(0.8-7.3)$ & $0.018^{*}$ \\
\hline \multicolumn{4}{|c|}{ Urge sensation, median (range) } \\
\hline Rectal volume (mL) & $185(45-660)$ & $265(70-505)$ & $0.028 *$ \\
\hline $\begin{array}{l}\text { Rectal pressure } \\
(\mathrm{mm} \mathrm{Hg})\end{array}$ & $48(23-78)$ & $52(28-85)$ & $0.014 *$ \\
\hline $\begin{array}{l}\text { Rectal compliance (mL/ } \\
\text { mmH g) }\end{array}$ & $4.4(0.9-16.9)$ & $5.3(1.5-9.3)$ & 0.248 \\
\hline \multicolumn{4}{|c|}{ Maximum tolerable volume, median (range) } \\
\hline Rectal volume (mL) & $245(65-885)$ & $360(160-760)$ & $<0.001 * *$ \\
\hline $\begin{array}{l}\text { Rectal pressure } \\
\quad(\mathrm{mm} \mathrm{Hg})\end{array}$ & $52(27-84)$ & $66(25-103)$ & $<0.001 * *$ \\
\hline $\begin{array}{l}\text { Rectal compliance }(\mathrm{mL} / \\
\mathrm{mmH} \text { g) }\end{array}$ & $4.9(1.0-16.5)$ & $5.8(2.7-10.4)$ & $0.020^{*}$ \\
\hline
\end{tabular}

* Statistical significance of $P<0.05$

** Statistical significance of $P<0.005$

is also displayed graphically for both rectal sensation levels and MTVs. Moreover, the correlations between rectal volume and rectal pressure calculated separately for the three patients' subgroups were comparable with the correlations found in the total patients' group (Appendix, Fig. 5).

To exclude the possible influence of sex or age on the outcomes of our analyses, we analyzed whether there was a correlation between these demographic variables and rectal volumes and pressures. In both groups, we found very weak correlations between sex and rectal volumes and pressures at all the sensation levels investigated and MTVs (Table 3). Similarly, for both groups, we found very weak correlations between age and rectal volumes and pressures at each rectal sensation level and MTVs (Table 3).

\section{Discussion}

Our study demonstrates that in both patients with defecation problems and healthy participants rectal volumes vary considerably at each rectal sensation level and MTV.
Contrastingly, rectal pressures at the different rectal sensation levels and MTVs were distributed normally in the patients and the healthy participants. Moreover, our study demonstrated that rectal volume and rectal pressure were not correlated, in other words patients with increased rectal volumes did not perceive increased rectal pressures to obtain certain rectal filling sensations. This finding confirmed that rectal volume and rectal pressure are independent entities. Additionally, we found no correlation between rectal volume or pressure and age or sex, two demographic factors known to influence anorectal physiology.

Earlier studies identified rectal pressure as the main trigger for the rectal filling sensation $[5,9,14,18]$. Together with our finding that rectal pressure operated independently of rectal volume, the notion that rectal volume thresholds are not associated with the rectal filling sensation was also supported. Nevertheless, during current clinical investigations of rectal filling sensations, patients' rectal volume thresholds are registered, at which a certain filling sensation is perceived $[2-4,8,19,20]$. In such situations, when only volume-based sensory thresholds are used to test rectal filling sensation, all patients with an increased rectal volume will be diagnosed with decreased rectal sensation, i.e., rectal hyposensitive $[1,6,8,9]$.

Given the fact that patients who suffer from chronic constipation often have increased rectal volumes [5, 7], many of them will automatically be diagnosed with rectal hyposensitivity according to the currently used volume-based investigation, even though rectal sensation is not impaired in all of these patients $[9,21]$.

Besides, our study shows that healthy participants, who did not admit to experiencing any anorectal dysfunctions, had even higher rectal volumes than the patients. Although the reasons for this phenomenon are unclear, they cannot result from technical differences because all participants underwent tests that were performed in exactly the same way. Possibly, the rectal volumes of the patients were not higher than those of the healthy participants, because some patients suffered from incontinence and not from constipation, and the constipated patients used laxatives or rectal irrigations regularly. The important point, however, is that the healthy participants, although they had higher rectal volumes than patients, did not suffer from rectal hyposensitivity. Therefore, in our opinion, the diagnostic process of hyposensitivity, which currently takes rectal volume into account, should be reconsidered. Our findings support previous reports using pressure-controlled measurements, i.e., barostat, that also postulate that an increased rectal volume might lead to misdiagnosis considering the status of nerve sensitivity, when volume-based thresholds are used in the diagnosis of hyposensitivity $[1,9]$.

The patients who are currently being diagnosed with rectal hyposensitivity actually consist of two distinct groups: one with increased rectal volumes without sensory 
Constant sensation

A

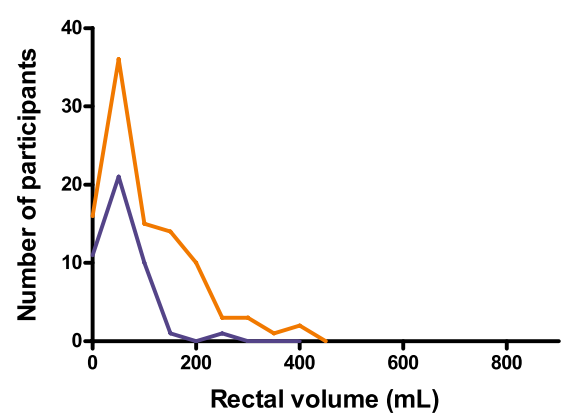

D

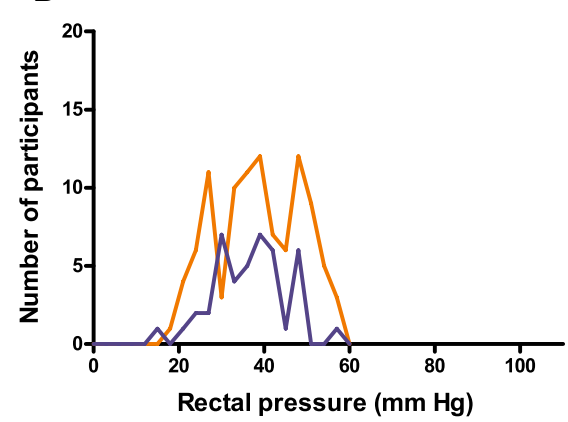

Urge sensation

B

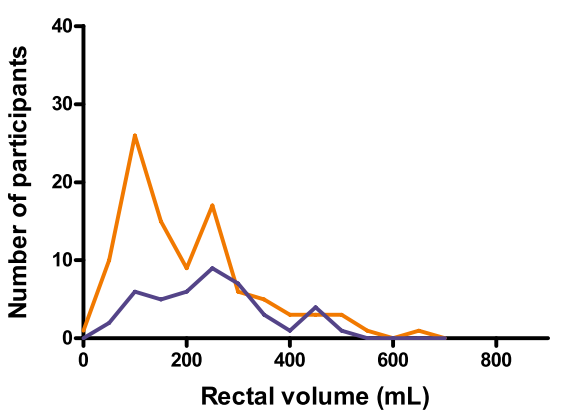

E

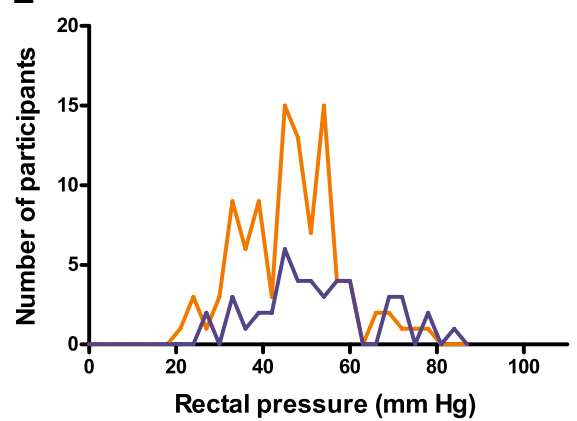

Maximal tolerable volume

C

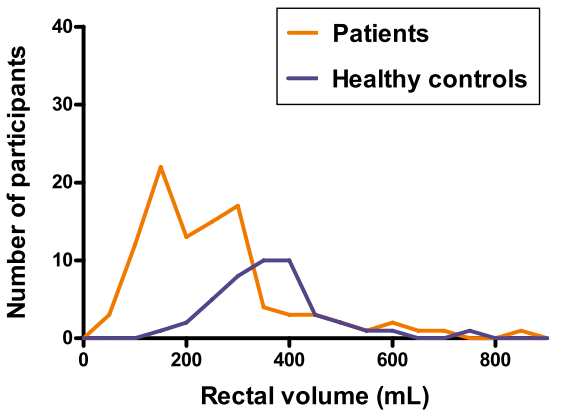

$\mathbf{F}$

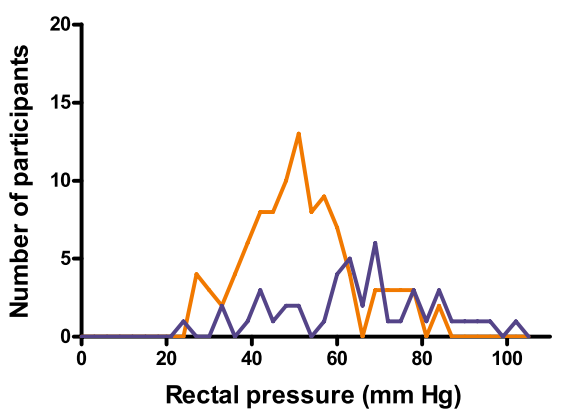

Fig. 2 Distribution of rectal volumes and pressures at different rectal sensation levels and MTV. There is no normal distribution of the rectal volumes of patients (indicated in red) and healthy controls (indicated in blue) at CS (a), US (b) and MTV (c). However, the rec-

Table 2 Normality of the distributions of rectal volumes and pressures at the different rectal sensation levels and MTV

Patients $(n=100) \quad \begin{aligned} & \text { Healthy con- } \\ & \text { trols }(n=44)\end{aligned}$

\begin{tabular}{lcc}
\hline Rectal volumes $(P$ value $)$ & & \\
Constant sensation & $<0.001^{* *}$ & $<0.001^{* *}$ \\
Urge sensation & $<0.001^{* *}$ & 0.266 \\
Maximum tolerable volume & $<0.001^{* *}$ & $0.024^{*}$ \\
Rectal pressures $(P$ value $)$ & & \\
Constant sensation & $0.039^{*}$ & 0.979 \\
Urge sensation & 0.248 & 0.296 \\
Maximum tolerable pressure & 0.072 & 0.914 \\
\hline
\end{tabular}

* Statistical significance of $P<0.05$ (difference from a normal distribution of data)

**Statistical significance of $P<0.005$ (difference from a normal distribution of data)

impairments and the other with increased rectal volumes with sensory impairments. When taking rectal volume thresholds into account, both groups of patients will be diagnosed as being rectally hyposensitive, while in fact only the second group of patients is truly hyposensitive in terms of sensory impairment. Therefore, among the patients who are tal pressure distributions at CS (d), US (e) and MTV (f) resembles the Bell curve, indicating normal distributions in both patients and healthy controls

currently diagnosed with rectal hyposensitivity, we would prefer to distinguish between, (a) patients with rectal hyposensitivity who have diminished rectal filling sensations because of sensory impairments, and (b) rectal hypervolumetric patients who have enlarged rectal volumes without sensory problems. Of course, patients with a combination of both will also occur.

Because our study showed that either no, or a very weak correlation between rectal volumes and pressures exists at different rectal sensation levels and MTV, and since we know that rectal pressure determines rectal filling sensations, we think that during gradual distention of the rectum, the rectal filling sensation should be determined according to the measured rectal pressure thresholds at which the sensations are reported, and not the rectal volumes. Rectal volume thresholds should only be used to investigate possible rectal enlargement or dilatation.

In general, the manometric data of the patients in this study were comparable to the outcomes reported by other researchers who had also used anorectal manometry [3, $14,18]$, which is not surprising since the balloon retention test was proved to be highly reproducible $[5,6]$. In order to measure rectal sensitivity, either anorectal manometry or a barostat can be used, provided rectal pressure thresholds are 
A Constant sensation

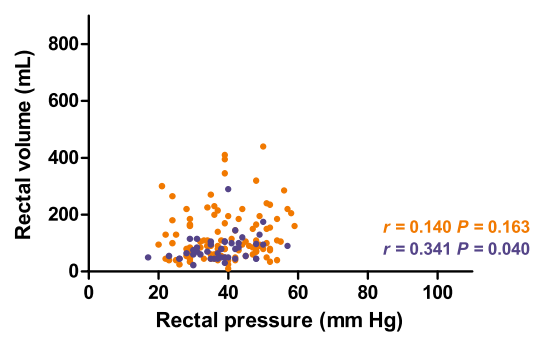

B Urge sensation

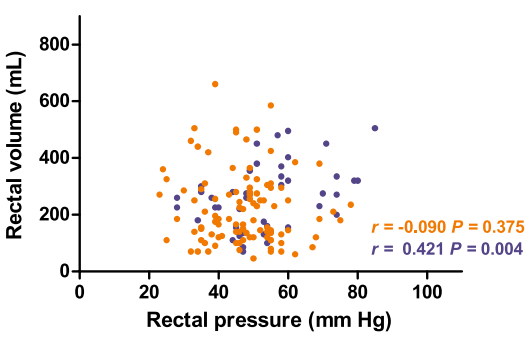

C Maximal tolerable volume

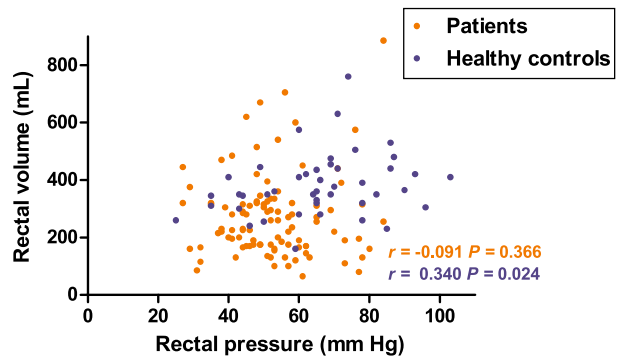

Fig. 3 Analysis of the correlation between rectal volumes and pressures at different rectal sensation levels and MTV. Analysis of the correlation between rectal volumes and pressures in patients (indicated in red) and healthy controls (indicated in blue) at CS (a), US (b), and MTV (c)

used to determine rectal sensitivity and not rectal volume thresholds $[1,3,6,22]$.

\section{Limitations}

It is notable that a large percentage of studies on rectal hyposensitivity focus on rectal compliance. Because calculating rectal compliance is based on rectal pressure and volume, and because we investigated whether a correlation existed between these two parameters, we did not include a broad analysis of rectal compliance in this study.

Table 3 Correlation of demographic variables with rectal volumes and pressures

\begin{tabular}{|c|c|c|c|c|}
\hline \multirow[t]{2}{*}{ Correlation variables } & \multicolumn{2}{|c|}{ Patients $(n=100)$} & \multicolumn{2}{|c|}{$\begin{array}{l}\text { Healthy controls } \\
(n=44)\end{array}$} \\
\hline & $r$ value & $P$ value & $r$ value & $P$ value \\
\hline \multicolumn{5}{|l|}{ Rectal volumes versus sex } \\
\hline Constant sensation & -0.163 & 0.105 & 0.168 & 0.275 \\
\hline Urge sensation & -0.088 & 0.381 & -0.004 & 0.981 \\
\hline Maximal tolerable volume & -0.058 & 0.568 & -0.055 & 0.722 \\
\hline \multicolumn{5}{|l|}{ Rectal pressures versus sex } \\
\hline Constant sensation & -0.139 & 0.167 & -0.241 & 0.120 \\
\hline Urge sensation & -0.114 & 0.259 & -0.423 & $0.004 * *$ \\
\hline Maximal tolerable pressure & -0.147 & 0.145 & -0.210 & 0.172 \\
\hline \multicolumn{5}{|l|}{ Rectal volumes versus age } \\
\hline Constant sensation & -0.008 & 0.936 & -0.263 & 0.084 \\
\hline Urge sensation & -0.088 & 0.382 & 0.075 & 0.630 \\
\hline Maximal tolerable volume & -0.104 & 0.304 & 0.102 & 0.512 \\
\hline \multicolumn{5}{|l|}{ Rectal pressures versus age } \\
\hline Constant sensation & 0.174 & 0.083 & 0.014 & 0.928 \\
\hline Urge sensation & 0.197 & 0.050 & 0.152 & 0.325 \\
\hline Maximal tolerable pressure & 0.119 & 0.239 & 0.077 & 0.618 \\
\hline
\end{tabular}

**Statistical significance of $P<0.005$
Moreover, the patients in this study were given bowel preparation before the measurements. However, the healthy controls did not use an enema. The lack of bowel preparation in the healthy control group might have had an influence on the results.

\section{Conclusions}

The current nomenclature of rectal hyposensitivity should be reconsidered because participants with increased rectal volumes do not experience increased rectal pressures at different rectal filling sensations, and because earlier rectal pressure has been proven to be the trigger for rectal filling sensations. Rectal pressure thresholds should be used for the diagnosis of rectal hyposensitivity instead of rectal volume thresholds.

In our opinion, "rectal hyposensitivity" should be reserved for patients with impaired rectal sensation and not for patients who report rectal sensations at "abnormally" increased rectal volume thresholds.

Acknowledgments The authors thank Ms. O. J. Pras, Ms. T. de Groot, Ms. S. Gerritsen, and Mrs. B. Brongers-Posthuma of the Anorectal Physiology Laboratory for their substantial assistance in performing the measurements. In addition, we would like to thank T. van Wulfften Palthe, Ph.D., for correcting the English manuscript.

Author's contribution PMAB, MT, and SJV have given substantial contributions to concept and design of the work, acquisition, analysis and interpretation of data. SJV, MT, and PMAB involved in drafting of the article and critical revision for important intellectual content. SJV, MT, and PMAB approved the version of the manuscript to be published.

Funding The authors received no financial support for the research.

\section{Compliance with ethical standards}

Conflict of interest The authors declare that they have no conflict of interest. 
Ethical approval All procedures performed in studies involving human participants were in accordance with the ethical standards of the institutional and/or national research committee and with the 1964 Helsinki Declaration and its later amendments or comparable ethical standards.

Open Access This article is distributed under the terms of the Creative Commons Attribution-NonCommercial 4.0 International License (http://creativecommons.org/licenses/by-nc/4.0/), which permits any noncommercial use, distribution, and reproduction in any medium, provided you give appropriate credit to the original author(s) and the source, provide a link to the Creative Commons license, and indicate if changes were made.

\section{Appendix}

See Figs. 4 and 5.

\section{Constant sensation}

A
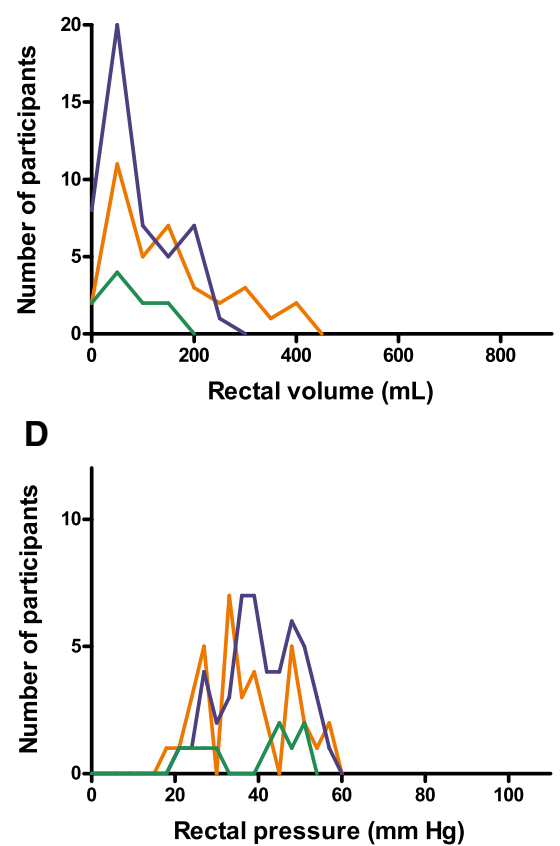

Urge sensation

B

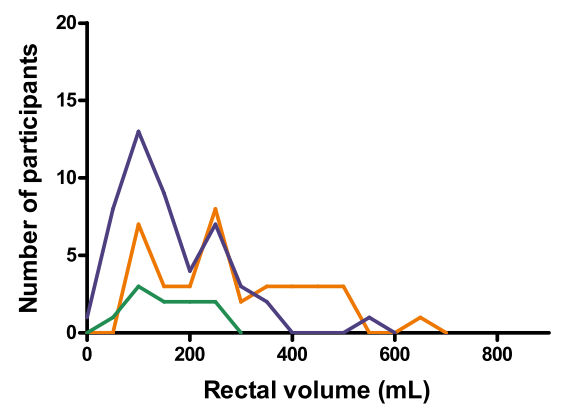

E

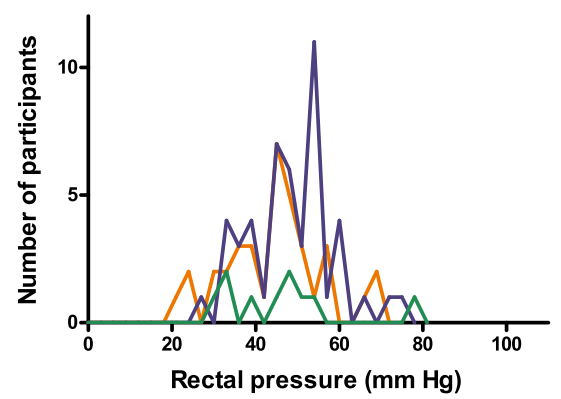

Maximal Tolerable Volume

C
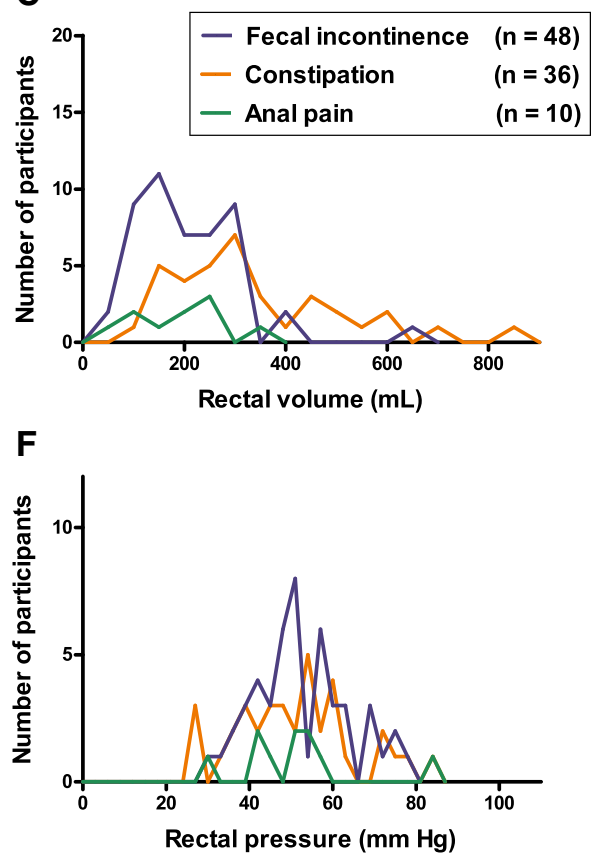

Fig. 4 Distribution of rectal volumes and pressures at different rectal sensation levels and MTV in patients only. Patients were divided into three subgroups based on their clinical presentation (fecal incontinence, constipation, and anal pain)

A Constant sensation

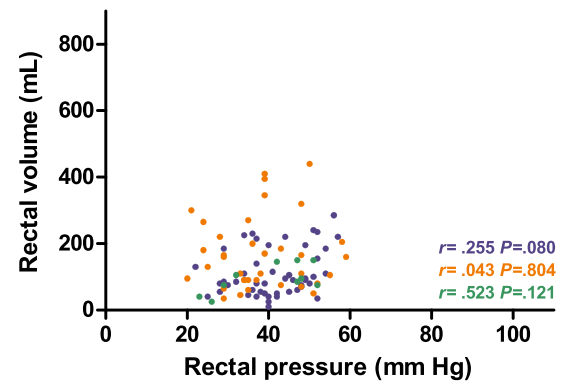

B Urge sensation

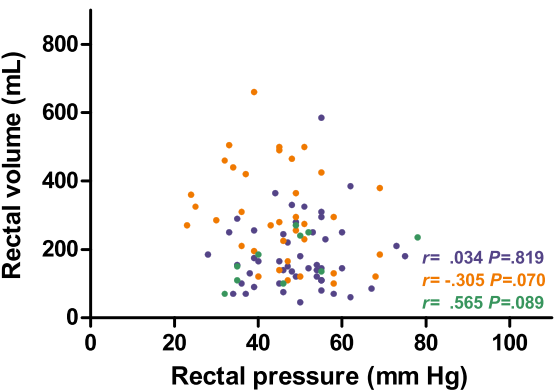

C Maximal tolerable volume

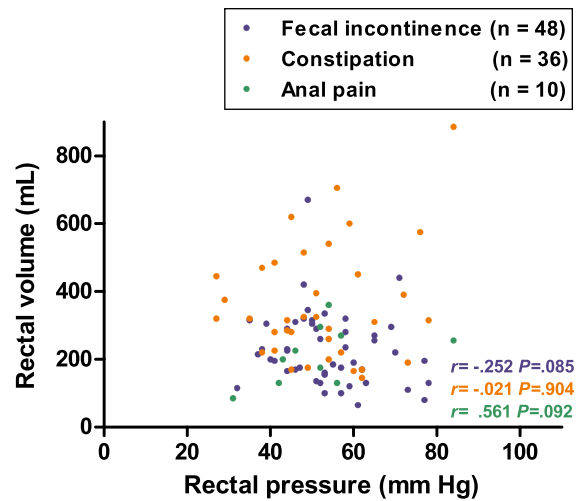

Fig. 5 Analysis of the correlation between rectal volumes and pressures at different rectal sensation levels and MTV in patients only 


\section{References}

1. Gladman MA, Aziz Q, Scott SM, Williams NS, Lunniss PJ. Rectal hyposensitivity: Pathophysiological mechanisms. Neurogastroenterol Motil. 2009;21:e4-e5.

2. Burgell RE, Scott SM. Rectal hyposensitivity. J. Neurogastroenterol Motil. 2012;18:373-384.

3. Wijffels NA, Angelucci G, Ashrafi A, Jones OM, Cunningham C, Lindsey I. Rectal hyposensitivity is uncommon and unlikely to be the central cause of obstructed defecation in patients with high-grade internal rectal prolapse. Neurogastroenterol Motil. 2011;23:e30.

4. Gladman MA, Scott SM, Williams NS, Lunniss PJ. Clinical and physiological findings, and possible aetiological factors of rectal hyposensitivity. Br J Surg. 2003;90:860-866.

5. Broens PM, Penninckx FM, Lestar B, Kerremans RP. The trigger for rectal filling sensation. Int J Colorectal Dis. 1994;9:1-4.

6. Scott SM, Gladman MA. Manometric, sensorimotor, and neurophysiologic evaluation of anorectal function. Gastroenterol Clin North Am. 2008;37:511-538.

7. Mody R, Guerin A, Fok B, et al. Prevalence and risk of developing comorbid conditions in patients with chronic constipation. Curr Med Res Opin. 2014;30:2505-2513.

8. Gladman MA, Lunniss PJ, Scott SM, Swash M. Rectal hyposensitivity. Am J Gastroenterol. 2006;101:1140-1151.

9. Gladman MA, Dvorkin LS, Lunniss PJ, Williams NS, Scott SM. Rectal hyposensitivity: A disorder of the rectal wall or the afferent pathway? an assessment using the barostat. Am J Gastroenterol. 2005;100:106-114.

10. Hammer HF, Phillips SF, Camilleri M, Hanson RB. Rectal tone, distensibility, and perception: Reproducibility and response to different distensions. Am J Physiol. 1998;274:G584-G590.

11. Palit Somnath S. The physiology of human defecation. Dig Dis Sci. 2012;57:1445-1464. https://doi.org/10.1007/s1062 0-012-2071-1.
12. van den Berg MM, Voskuijl WP, Boeckxstaens GE, Benninga MA. Rectal compliance and rectal sensation in constipated adolescents, recovered adolescents and healthy volunteers. Gut. 2008;57:599-603.

13. Carrington EV, Heinrich $\mathrm{H}$, Knowles $\mathrm{CH}$, et al. Methods of anorectal manometry vary widely in clinical practice: Results from an international survey. Neurogastroenterol Motil. 2017;29:https ://doi.org/10.1111/nmo.13016. Epub Jan 182017.

14. Sloots CE, Felt-Bersma RJ, Cuesta MA, Meuwissen SG. Rectal visceral sensitivity in healthy volunteers: Influences of gender, age and methods. Neurogastroenterol Motil. 2000;12:361-368.

15. Broens P, Vanbeckevoort D, Bellon E, Penninckx F. Combined radiologic and manometric study of rectal filling sensation. Dis Colon Rectum. 2002;45:1016-1022.

16. Meinds RJ, van Meegdenburg MM, Trzpis M, Broens PM. On the prevalence of constipation and fecal incontinence, and their co-occurrence, in the Netherlands. Int J Colorectal Dis. 2017;32:475-483.

17. van Meegdenburg MM, Heineman E, Broens PM. Pudendal neuropathy alone results in urge incontinence rather than in complete fecal incontinence. Dis Colon Rectum. 2015;58:1186-1193.

18. Broens P, Penninckx F. Filling sensations after restorative proctocolectomy. Acta Chir Belg.. 2002;102:20-23.

19. Camilleri M. Testing the sensitivity hypothesis in practice: Tools and methods, assumptions and pitfalls. Gut. 2002;51:i34-i40.

20. Meunier P, Mollard P, Marechal JM. Physiopathology of megarectum: The association of megarectum with encopresis. Gut. 1976; 17:224-227.

21. Madoff RD, Orrom WJ, Rothenberger DA, Goldberg SM. Rectal compliance: A critical reappraisal. Int J Colorectal Dis. 1990;5:37-40.

22. Diamant NE, Kamm MA, Wald A, Whitehead WE. AGA technical review on anorectal testing techniques. Gastroenterology. 1999;116:735-760. 